\title{
Consumo de nutrientes, produção e composição do leite de cabras da raça Alpina alimentadas com dietas contendo diferentes teores de fibra ${ }^{1}$
}

\author{
Sérgio Carvalho ${ }^{2}$, Marcelo Teixeira Rodrigues ${ }^{3}$, Renata Helena Branco ${ }^{4}$, Carla Aparecida \\ Florentino Rodrigues ${ }^{4}$
}

\footnotetext{
${ }^{1}$ Parte da tese de Doutorado em Zootecnia do primeiro autor.

2 Grupo de Pesquisa em Agronegócios do Centro Universitário Feevale - Novo Hamburgo/RS.

${ }^{3}$ Departamento de Zootecnia da Universidade Federal de Viçosa/MG.
}

${ }^{4}$ Doutor em Zootecnia da Universidade Federal de Viçosa.

RESUMO - Foram utilizadas 50 cabras Alpinas em lactação objetivando-se avaliar os efeitos de diferentes teores de fibra em detergente neutro proveniente da forragem (FDNF) sobre o consumo de nutrientes, a produção e a composição do leite. Os animais foram confinados em baias individuais e distribuídos aleatoriamente em um delineamento experimental inteiramente casualizado, com cinco tratamentos e dez repetições. Foi utilizada uma ração em mistura completa, composta de feno de tifton85 (Cynodon sp.), fubá de milho, farelo de soja e mistura mineral. As dietas experimentais continham 20, 27, 34, 41 ou 48\% de FDNF. Com o aumento da FDNF das dietas, houve redução linear dos consumos de MS, MO, CHT, CNE e energia líquida (EL), além de aumento linear dos consumos de FDN, FDN proveniente da forragem (FDNF) e FDA. Não foi observado efeito do teor de FDNF sobre o teor de gordura e de sólidos totais do leite. A produção de leite (corrigida e não corrigida) e de sólidos totais diminuiu linearmente. A eficiência de utilização da energia metabolizável consumida para produção de leite atingiu o plateau com uma dieta contendo $35,4 \%$ de FDNF.

Palavras-chave: alimentação, caprinos, fibra, forragem

\section{Nutrient intake and milk yield and composition of Alpine lactating goats fed diets with different fiber levels}

\begin{abstract}
Fifty Alpine lactating does were used to evaluate the effects of feeding different levels of forage neutral detergent fiber (FNDF) on nutrient intake and milk yield and composition. Animals were housed individually and assigned to a completely randomized design with five treatments and ten replicates. A total mixed ration, containing Tifton-85 (Cynodon sp.) hay, ground corn, soybean meal and mineral mixture was fed ad libitum. The experimental diets contained 20, 27, 34, 41 or $48 \%$ of FNDF. As dietary FNDF increased, the intakes of DM, OM, CP, EE, TC, NSC and net energy (NE) decreased linearly. In addition, increasing dietary FNDF linearly increased intakes of NDF, FNDF and ADF. There was no effect of FNDF level on contents of milk fat and milk total solids. However, milk yield, fat-corrected milk and yield of total solids all decreased linearly. The efficiency of utilization of metabolizable energy to milk yield reached a plateau at $35.4 \%$ of FNDF.
\end{abstract}

Key Words: feeding, fiber, forage, goats

\section{Introdução}

O consumo voluntário pode ser definido como a quantidade máxima de MS ingerida por um animal ou grupo de animais durante determinado período no qual há livre acesso ao alimento (Forbes, 1995). Em um sistema de produção, o consumo de alimento é de grande importância, visto que a ingestão de MS determina o fornecimento de nutrientes necessários para atender os requerimentos de mantença e produção dos animais.

Segundo Rodrigues (1998), o consumo de nutrientes é o principal fator a limitar a produção de ruminantes. Portanto, maximizar o consumo de um animal é fundamental no desen-

Correspondências devem ser enviadas para: sergiocarvalho@feevale.br volvimento de rações e estratégias de alimentação que otimizarão a rentabilidade da produção.

Mertens (1994) afirma que a ingestão de MS é controlada por fatores físicos, fisiológicos e psicogênicos. $\mathrm{O}$ fator físico refere-se à distensão física do rúmen-retículo, o fisiológico é regulado pelo balanço energético ou nutricional e a regulação psicogênica envolve o comportamento animal em resposta a fatores inibidores ou estimuladores no alimento ou ao manejo alimentar, que não são relacionados ao valor energético do alimento ou ao efeito de repleção.

Entre os fatores envolvidos na regulação do consumo, a concentração de FDN na dieta de ruminantes tem sido considerada, por sua lenta degradação e por apresentar 
reduzida taxa de passagem no ambiente ruminal. Esses fatores podem limitar a ingestão de alimento, em virtude da possibilidade de repleção ruminal. Se a ingestão é reduzida pela limitação física, alimentos com alto teor de FDN, como os volumosos, poderão ter sua ingestão restringida, limitando a expressão do potencial genético do animal para produção.

Por outro lado, quando se utilizam rações com baixa proporção de FDN e alto teor de energia, a demanda fisiológica do animal pode limitar a ingestão (Mertens, 1983). Nesse caso, o animal consome alimento para manter ingestão constante de energia, podendo diminuir a ingestão de MS com um aumento da digestibilidade do alimento, visto que maior quantidade de energia estará disponível para ser utilizada pelo animal.

Quando fornecidas dietas de alta qualidade, o animal consome para atingir sua demanda energética e o consumo é limitado pelo potencial genético do animal para utilizar a energia absorvida. Entretanto, quando fornecidas dietas de baixa qualidade (alto conteúdo de FDN), o animal consome alimento até atingir a capacidade do rúmen-retículo (Mertens, 1994).

Portanto, a relação da ingestão de MS com o conteúdo de FDN da ração pode ser interpretada como sendo quadrática, indicando a existência de um ponto de inflexão ou transição entre os controles físico e fisiológico, em que o efeito da repleção causado pela presença de fibra sobre a ingestão cessa, ocorrendo então o controle do consumo pela ingestão de energia (Bull et al., 1976).

A formulação de dietas com base na FDN, como uma porcentagem de MS da ração, tem sido recomendada em razão do relacionamento positivo entre FDN e repleção ruminal e do relacionamento negativo entre FDN e densidade energética do alimento (Mertens, 1994).

Considerando o conceito proposto por Mertens (1983), uma dieta com $35 \%$ de FDN seria capaz de estimular o máximo consumo de MS e fibra para vacas produzindo de 25 a $30 \mathrm{~L}$ de leite. Altas concentrações de FDN limitariam o consumo, em decorrência da distensão física do rúmenretículo, enquanto o consumo de dietas com menor teor de FDN seria limitado ao se atingir o requerimento de energia do animal. Mertens (1987) sugere ainda o valor médio de $1,2 \%$ do peso vivo para expressar a ingestão ótima de FDN na ração de animais em lactação. O NRC (1989), por sua vez, recomenda para vacas leiteiras de alta produção 25 a $28 \%$ de FDN na dieta, sendo que, no mínimo, $75 \%$ da FDN deve ser proveniente de forragens. As atuais recomendações do NRC (2001) sugerem mínimo de 25 a 33\% de FDN na dieta, dependendo da proporção de FDN proveniente da forragem.
Entretanto, a observação de Mertens (1996) de que vacas alimentadas com rações com a mesma concentração de FDN podem não ter o mesmo consumo serve para ilustrar que a relação entre FDN e consumo é complexa e depende não somente da FDN, como também da curva de exigência do animal. Logo, o ponto em que o nível de FDN da ração deixa de limitar fisicamente a ingestão é determinado, primariamente, pelo nível de produção do animal (NRC, 1989).

Atualmente, não existem na literatura dados disponíveis sobre recomendações e níveis ótimos de fibra para a espécie caprina. Em razão da escassez de informações, tem-se seguido, portanto, orientações fornecidas em tabelas específicas para bovinos, como o NRC (1989) e NRC (2001).

O grande problema em utilizar informações obtidas com bovinos é que as exigências de proteína, energia e minerais são diferentes entre as espécies. Além disso, as atividades de mastigação, o tempo de retenção de partículas no rúmen e a produção de substâncias tamponantes pela saliva são também diferentes, o que torna o uso dos dados dessas tabelas teoricamente errado e sem conseqüência prática. Para elaboração de rações balanceadas para caprinos visando máxima eficiência animal é fundamental que os níveis de fibra sejam estabelecidos.

O objetivo neste trabalho foi estudar o efeito de dietas com diferentes níveis de fibra em detergente neutro proveniente da forragem sobre o consumo de nutrientes, a produção e a composição do leite, a fim de se estabelecerem limites máximos e mínimos recomendáveis de fibra nas rações para cabras em lactação.

\section{Material e Métodos}

O experimento foi realizado no Setor de Caprinocultura do Departamento de Zootecnia, do Centro de Ciências Agrárias da Universidade Federal de Viçosa, no período de 30 de maio a 29 de setembro de 2000.

Cinqüenta cabras Alpinas em lactação (peso vivo médio de $57,73 \mathrm{~kg}$ ) foram utilizadas do $45^{\circ}$ dia após o parto até o $105^{\circ}$ dia de lactação, totalizando 60 dias experimentais. Os 45 dias iniciais da lactação serviram para adaptação dos animais às dietas, às instalações e ao manejo.

Os animais foram alimentados em baias individuais, providas de comedouro e bebedouro, com piso totalmente ripado, com dimensão de 1,5 x 2,0 m. As dietas foram fornecidas duas vezes ao dia, às $8 \mathrm{~h} 30$ e $16 \mathrm{~h} 30$.

$\mathrm{O}$ delineamento experimental utilizado foi em esquema inteiramente casualizado, com cinco tratamentos e dez repetições, sendo a unidade experimental representada pelo animal. 
Foram testadas cinco dietas constituídas por diferentes teores de FDNF, corrigida para cinzas, $(20,27,34,41$ e 48\%), com base na MS. Foi utilizada uma ração em mistura completa de feno de tifton 85 (Cynodon sp.) + mistura concentrada. A proporção volumoso:concentrado variou de acordo com o tratamento, para se atingir o teor de FDNF pretendido para as dietas experimentais. O concentrado utilizado foi constituído por fubá de milho (Zea mays L.), farelo de soja (Glycine max L.), calcário calcítico, fosfato bicálcico, sal comum e premix mineral. As dietas utilizadas, isoprotéicas, continham $18 \%$ de PB na MS, conforme recomendações do AFRC (1993).

A composição percentual dos ingredientes nas dietas experimentais consta na Tabela 1 e a composição química das dietas experimentais na Tabela 2 .

O feno de tifton 85 (16,12\% de PB e 75,56 de FDN) foi picado em moinho de martelo, em partículas de 1 a $3 \mathrm{~cm}$, e armazenado em sacos. $\mathrm{O}$ alimento oferecido e as sobras foram pesados diariamente para controle do consumo diário de MS pelos animais. A quantidade oferecida foi ajustada de acordo com a sobra observada diariamente $(10 \%$ da quantidade fornecida no dia anterior), de modo a garantir o consumo voluntário máximo dos animais e evitar a seleção do alimento pelos animais.

Amostras dos alimentos e das sobras foram obtidas diariamente e formaram amostras compostas a cada 15 dias. As amostras compostas foram acondicionadas em sacos plásticos identificados e armazenadas em congelador a $-10^{\circ} \mathrm{C}$, sendo, posteriormente secas em estufa de circulação forçada, a $60 \pm 5^{\circ} \mathrm{C}$, por 72 horas (Silva, 1990). A seguir, foram proces-

Tabela 1 - Composição percentual dos ingredientes das dietas experimentais (\%MS)

Table 1 - Ingredient composition of the experimental diets on dry matter basis

\begin{tabular}{|c|c|c|c|c|c|}
\hline \multirow[t]{2}{*}{$\begin{array}{l}\text { Ingrediente ( } \% \text { MS) } \\
\text { Ingredient }(\% D M)\end{array}$} & \multicolumn{5}{|c|}{$\begin{array}{l}\text { Nível de FDNF } \\
\text { Level of FNDF }\end{array}$} \\
\hline & 20 & 27 & 34 & 41 & 48 \\
\hline $\begin{array}{l}\text { Feno de tifton } 85 \\
\text { Tifton } 85 \text { hay }\end{array}$ & 28,81 & 38,89 & 48,97 & 59,06 & 69,14 \\
\hline $\begin{array}{l}\text { Fubá de milho } \\
\text { Ground corn }\end{array}$ & 46,85 & 39,17 & 31,46 & 23,71 & 16,00 \\
\hline $\begin{array}{l}\text { Farelo de soja } \\
\text { Soybean meal }\end{array}$ & 21,84 & 19,54 & 17,25 & 14,96 & 12,67 \\
\hline $\begin{array}{l}\text { Calcário calcítico } \\
\text { Limestone }\end{array}$ & 1,74 & 1,64 & 1,56 & 1,36 & 1,18 \\
\hline $\begin{array}{l}\text { Fosfato bicálcico } \\
\text { Dicalcium phosfate }\end{array}$ & 0 & 0 & 0 & 0,15 & 0,25 \\
\hline $\begin{array}{l}\text { Sal comum } \\
\text { Salt }\end{array}$ & 0,74 & 0,74 & 0,74 & 0,74 & 0,74 \\
\hline Premix ${ }^{1}$ & 0,02 & 0,02 & 0,02 & 0,02 & 0,02 \\
\hline
\end{tabular}

1 Composição (Composition): sulfato de zinco (zinc sulfate), $50 \%$; sulfato de cobre (copper sulfate), $41,6 \%$; sulfato de cobalto (cobalt sulfate), $2,8 \%$; selenito de sódio (sodium selenite), 2,8\%; iodato de potássio (potassium iodate), 2,8\%. sadas em moinho tipo Willey com peneira de $1 \mathrm{~mm}$ e armazenadas em frascos de vidro com tampa de polietileno.

Os teores de MS, MO, PB, EE, LIG (método do permanganato de potássio) e CIN foram determinados conforme Silva (1990). Os teores de FDN e FDA foram determinados segundo método proposto por Van Soest (1967), citado por Silva (1990). Os valores de carboidratos totais (CHT) foram obtidos pela diferença de 100 - (\%PB $+\% \mathrm{EE}+\% \mathrm{MM}$ ), como descrito por Sniffen et al. (1992), e os CNE, pela diferença de CHT - FDN corrigido para cinzas (FDNc).

O conteúdo de energia líquida (EL) do volumoso foi obtido utilizando-se a equação de Moe \& Tyrrel (1976): $\mathrm{EL}=0,0245 \times \% \mathrm{NDT}-0,12$. O NDT foi estimado utilizando-se a equação descrita por Van Soest (1994): NDT = DMS - cinzas total $+1,25$ extrato etéreo $+1,9$, em que DMS (digestibilidade da MS $)=((100-$ FDNc $x(0,98))+($ FDN total $\mathrm{x}$ digestibilidade da FDN) - 12,9. A digestibilidade da FDN corrigida para Kd e Kp foi obtida considerando-se

Tabela 2 - Composição bromatológica das dietas experimentais Table 2 - Chemical composition of the experimental diets

\begin{tabular}{|c|c|c|c|c|c|}
\hline \multirow[t]{2}{*}{ Item $(\%)$} & \multicolumn{5}{|c|}{$\begin{array}{l}\text { Nível de FDNF } \\
\text { Level of FNDF }\end{array}$} \\
\hline & 20 & 27 & 34 & 41 & 48 \\
\hline $\begin{array}{l}\text { Matéria seca } \\
\text { Dry matter }\end{array}$ & 84,65 & 84,27 & 83,90 & 83,53 & 83,15 \\
\hline $\begin{array}{l}\text { Matéria orgânica } \\
\text { Organic matter }\end{array}$ & 93,78 & 93,50 & 93,19 & 92,86 & 92,56 \\
\hline $\begin{array}{l}\text { Proteína bruta } \\
\text { Crude protein }\end{array}$ & 18,41 & 18,37 & 18,33 & 18,29 & 18,25 \\
\hline $\begin{array}{l}\text { Extrato etéreo } \\
\text { Ether extract }\end{array}$ & 2,35 & 2,23 & 2,10 & 1,98 & 1,86 \\
\hline $\begin{array}{l}\text { FDN total } \\
\text { Total NDF }\end{array}$ & 30,18 & 36,60 & 43,01 & 49,43 & 55,85 \\
\hline $\begin{array}{l}\text { FDNF } \\
F N D F\end{array}$ & 20,00 & 27,00 & 34,00 & 41,00 & 48,00 \\
\hline $\begin{array}{l}\mathrm{FDA} \\
A D F\end{array}$ & 17,97 & 21,55 & 25,13 & 28,71 & 32,28 \\
\hline $\begin{array}{l}\mathrm{CHT}^{2} \\
\text { Total carbohydrate }\end{array}$ & 73,02 & 72,9 & 72,76 & 72,59 & 72,45 \\
\hline $\begin{array}{l}\mathrm{CNE} \\
\mathrm{NSC}\end{array}$ & 46,57 & 40,41 & 34,24 & 28,03 & 21,85 \\
\hline $\begin{array}{l}\text { CNE:FDN total } \\
\text { Total NSC:NDF }\end{array}$ & $1,54: 1$ & $1,10: 1$ & $0,80: 1$ & $0,57: 1$ & $0,39: 1$ \\
\hline $\begin{array}{l}\text { Lignina } \\
\text { Lignin }\end{array}$ & 1,32 & 1,65 & 1,99 & 2,33 & 2,66 \\
\hline $\begin{array}{l}\text { Cinzas } \\
\text { Ash }\end{array}$ & 6,22 & 6,50 & 6,81 & 7,14 & 7,44 \\
\hline $\begin{array}{l}\text { Energia líquida }{ }^{1} \\
\text { Net energy }\end{array}$ & 1,59 & 1,49 & 1,38 & 1,27 & 1,16 \\
\hline $\begin{array}{l}\text { Cálcio } \\
\text { Calcium }\end{array}$ & 0,80 & 0,80 & 0,80 & 0,80 & 0,80 \\
\hline $\begin{array}{l}\text { Fósforo } \\
\text { Phosphorus }\end{array}$ & 0,3 & 0,3 & 0,3 & 0,3 & 0,3 \\
\hline
\end{tabular}

${ }^{1}$ Valor calculado segundo Moe \& Tyrrel (1976).

2 Valor calculado segundo Sniffen et al. (1992).

1 Calculated value according Moe \& Tyrrel (1976).

2 Calculated value according Sniffen et al. (1992). 
Kp de $0,05 \mathrm{~h}^{-1}$ e Kd de $0,0256 \mathrm{~h}^{-1}$. O valor de Kd foi obtido aplicando-se análise de regressão (Waldo, 1970) aos dados de digestibilidade da FDN, segundo Van Soest (1994), considerando-se tempo de digestão de 96 horas.

Foram realizadas nas sobras análises de MS, MO, PB, EE, FDN,FDA, CHT e CNE, bem como a estimativa daEL, utilizando-se os mesmos procedimentos da análise dos alimentos fornecidos, para estimativa de consumo dos nutrientes.

Os animais foram pesados no início e ao final do período experimental. Para melhor acompanhamento, realizaram-se pesagens intermediárias a cada sete dias. As cabras foram ordenhadas manualmente duas vezes ao dia, às 7 e $16 \mathrm{~h}$, efetuando-se o controle leiteiro individual a cada ordenha, mediante a pesagem do leite.

Semanalmente, foram realizadas análises dos teores de gordura no leite da manhã e da tarde utilizando-se butirômetro de GERBER, conforme procedimento descrito por Silva (1997). A densidade e a temperatura foram obtidas em termolactodensímetro. O teor de sólidos totais (ST) foi estimado pela fórmula de Fleishmann. O leite foi corrigido para 3,5\% de gordura (LCG 3,5\%), segundo Gaines (1928), adotando-se a seguinte equação: $\operatorname{LCG} 3,5 \%=(0,4255 \times \mathrm{kg}$ leite $)+[16,425 \times(\%$ gordura $\div 100) \times$ kg leite $]$. A correção do leite para $4 \%$ de gordura (LCG 4\%) foi realizada segundo o NRC (1989), empregando-se a equação: $\operatorname{LCG} 4 \%=(0,4 \times \mathrm{kg}$ leite $)+(15 \times \mathrm{kg}$ de gordura do leite) . A correção do leite para sólidos totais (LCST) foi realizada conforme descrito por Tyrrel \& Reid (1965), aplicando-se a equação: $\operatorname{LCST}=(12,3$ $\mathrm{x}$ g de gordura) $+(6,56 \mathrm{x} \mathrm{g}$ de sólidos não gordurosos $)$ $(0,0752 \times \mathrm{kg}$ de leite $)$.

A eficiência de utilização da EM consumida para produção de leite foi calculada pela diferença entre o consumo de EM e a produção de leite corrigida para 3,5\% de gordura, utilizando-se a equação: eficiência $=($ Elp/CEM $) \times 100$, em que Elp = energia líquida utilizada para a produção de leite e CEM = consumo de EM. A ELp foi estimada segundo o NRC (1989): ELp = PLCG 3,5\%*0,6879(Mcal). Para cálculo do CEM, transformou-se a EL da dieta em NDT, utilizando-se a equação NDT $=(E L$ calculada $+0,12) / 0,0245$, adaptada de Moe \& Tyrrel (1976). Posteriormente, transformou-se o NDT em energia digestível (ED), por meio da equação $\mathrm{ED}=$ (NDT/100) x 4,409, e a ED em energia metabolizável (EM), pela equação $\mathrm{EM}=\mathrm{ED}$ x 0,82, segundo o NRC (1989).

A análise estatística foi realizada de acordo com os procedimentos descritos por Searle (1971), utilizando-se a produção de leite inicial como covariável. Quando verificado efeito significativo da covariável $(\mathrm{P} \leq 0,05)$ pelo teste $\mathrm{F}$, realizaram-se análises de variância e de regressão, selecionando os modelos com base na significância dos coeficientes de regressão, a $5 \%$ de probabilidade.
Quando não houve efeito significativo da covariável $(\mathrm{P}<0,05)$, os dados foram interpretados por meio de análises de variância e regressão, utilizando-se o programa SAEG Sistema de Análises Estatísticas e Genéticas (UFV, 1997).

Os modelos foram selecionados com base no coeficiente de determinação e na significância dos coeficientes de regressão, a 5\% de probabilidade, utilizando-se o teste $\mathrm{F}$.

\section{Resultados e Discussão}

Os resultados concernentes aos consumos médios diários de MS, MO, PB, EE, CHT, CNE e EL são apresentados na Tabela 3, e os dados de consumo de FDN, FDNF e FDA, na Tabela 4.

Os consumos de MS e MO, expressos em kg/dia, \%PV e g/kg PV ${ }^{0,75}$, diminuíram linearmente com a elevação dos níveis de FDNF da ração, ocorrendo menor consumo, tanto de MS como de MO, nas rações com maior conteúdo de fibra. De forma inversa, os consumos de FDN, FDNF e FDA, nas diversas formas de expressão, apresentaram tendência linear crescente $(\mathrm{P}<0,01)$ com o aumento do nível de FDNF nas rações. Comportamento semelhante foi observado por Araújo et al. (1998) e por Bürger et al. (2000), que, em estudo com bovinos, também verificaram elevação no consumo de FDN com o aumento do teor de FDN da ração.

O consumo de fibra obtido neste experimento diverge daquele proposto por Van Soest (1994), que sugere que os animais atinjam capacidade máxima de ingestão de FDN, e por Resende et al. (2004), que não observaram diferenças na ingestão de FDN entre as rações para bovinos. O consumo de FDN variou linearmente de 1,09 a 1,94\% do PV, demonstrando que as cabras suportaram quantidades crescentes de fibra no rúmen, não se observando valor limite para os animais até o nível estudado. É provável que a fibra tenha contribuído para a redução no consumo de MS por meio da redução nos parâmetros de cinética de degradação e de trânsito. Ao avaliar os valores de $\mathrm{R}^{2}$ apresentados na Tabela 3 para as equações que estimam o consumo de MS, verifica-se sua pequena magnitude, que pode ser explicada pela capacidade de adaptação das cabras a maiores quantidades de fibra. Todavia, observou-se maior correlação entre os níveis de fibra com o consumo de energia.

O valor observado para a ingestão de FDN $(1,53 \pm 0,4 \%$ do PV) encontra-se acima do recomendado pelo NRC (1989) para bovinos leiteiros. Para animais em lactação, o valor máximo de $1,2 \% \pm 0,1 \% \mathrm{PV}$ tem sido sugerido, porém, para caprinos estes valores não estão bem definidos e é possível que sejam diferentes daqueles sugeridos para bovinos, face às diferenças no comportamento ingestivo e na capacidade de processamento da fibra no trato 
Tabela 3 - Consumos médios de MS, MO, PB, EE, CHT, CNE e EL, de acordo com os teores de FDNF das dietas experimentais Table 3 - Average intakes of DM, OM, CP, EE, CHO, NSC, and NE according to the dietary FNDF levels

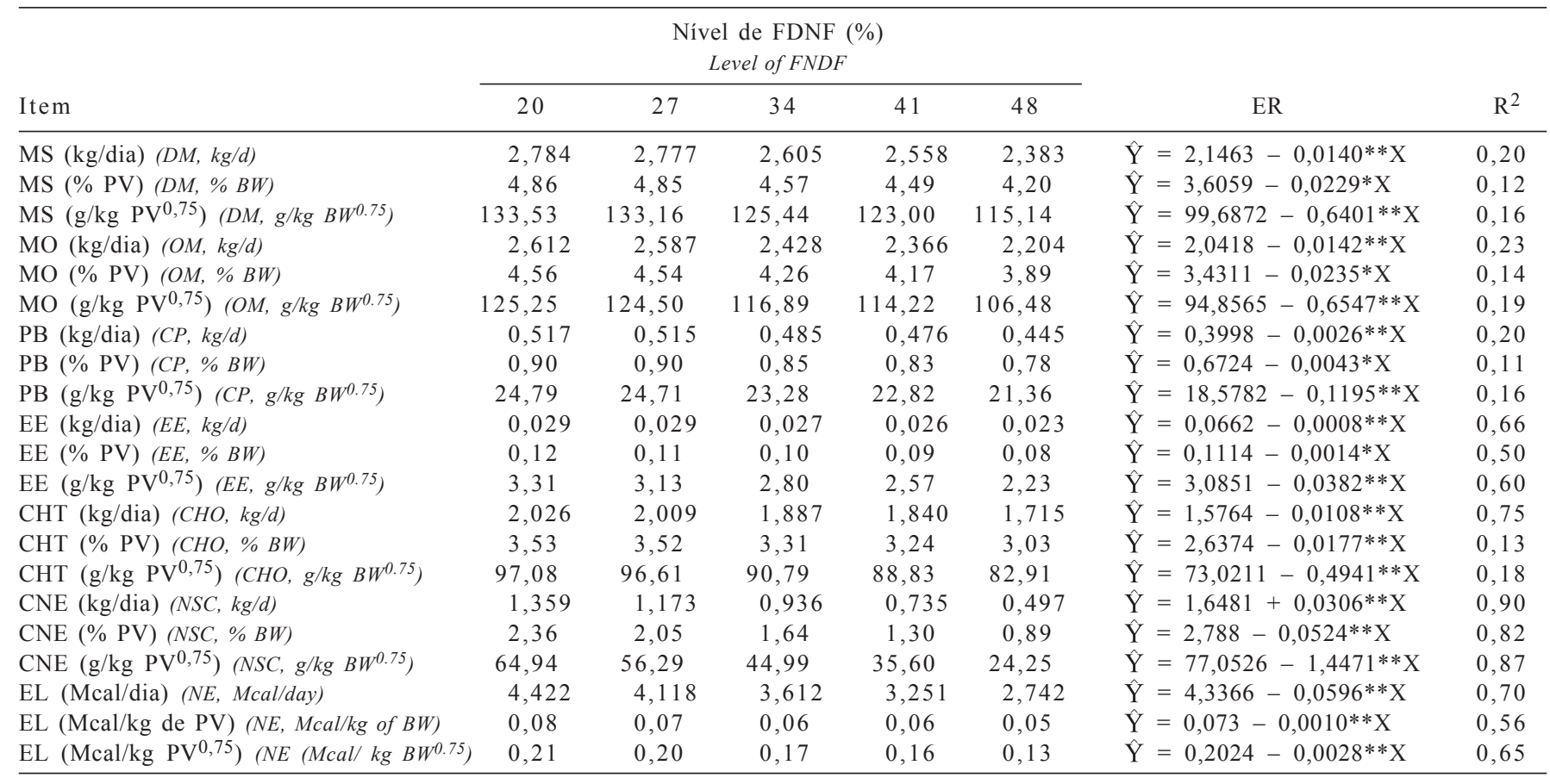

${ }^{*} \mathrm{e}^{* *}$ significativo a 5 e $1 \%$ de probabilidade, respectivamente, pelo teste $\mathrm{F}$.

${ }^{*}$ and ${ }^{* *}$ significant at 5 and $1 \%$ probability, respectively, by $F$ test.

Tabela 4 - Consumos médios de FDN, FDNF e FDA, de acordo com os teores de FDNF das dietas experimentais Table 4 - Average intakes of NDF, FNDF, and ADF according to the dietary FNDF levels

\begin{tabular}{|c|c|c|c|c|c|c|c|}
\hline \multirow[b]{2}{*}{ Item } & \multicolumn{5}{|c|}{$\begin{array}{l}\text { Nível de FDNF (\%) } \\
\text { Level of FNDF }\end{array}$} & \multirow[b]{2}{*}{ ER } & \multirow[b]{2}{*}{$\mathrm{R}^{2}$} \\
\hline & 20 & 27 & 34 & 41 & 48 & & \\
\hline FDN (\% PV) $(N D F, \% B W)$ & 1,09 & 1,36 & 1,53 & 1,77 & 1,94 & $\hat{Y}=-0,1290+0,0302 * * X$ & 0,68 \\
\hline $\mathrm{FDN}\left(\mathrm{g} / \mathrm{kg} \mathrm{PV} \mathrm{V}^{0,75}\right)\left(N D F, \mathrm{~g} / \mathrm{kg} B W^{0.75}\right)$ & 30,02 & 37,32 & 41,95 & 48,49 & 53,07 & $\hat{\mathrm{Y}}=-3,4311+0,8291 * * \mathrm{X}$ & 0,74 \\
\hline $\operatorname{FDNF}(\mathrm{kg} / \mathrm{dia})(F N D F, \mathrm{~kg} / \mathrm{d})$ & 0,472 & 0,643 & 0,767 & 0,925 & 1,048 & $\hat{\mathrm{Y}}=-0,2381+0,0207 * * \mathrm{X}$ & 0,83 \\
\hline FDA $(\mathrm{kg} / \mathrm{dia})(A D F, \mathrm{~kg} / \mathrm{d})$ & 0,424 & 0,518 & 0,578 & 0,662 & 0,721 & $\hat{\mathrm{Y}}=-0,0092+0,0107 * * \mathrm{X}$ & 0,69 \\
\hline FDA $(\% \mathrm{PV})(A D F, \% B W)$ & 0,74 & 0,91 & 1,01 & 1,16 & 1,27 & $\hat{\mathrm{Y}}=-0,0355+0,0188 * * \mathrm{X}$ & 0,63 \\
\hline $\mathrm{FDA}\left(\mathrm{g} / \mathrm{kg} \mathrm{PV}{ }^{0,75}\right)\left(A D F, \mathrm{~g} / \mathrm{kg} B W^{0.75}\right)$ & 20,38 & 24,96 & 27,80 & 31,89 & 34,71 & $\hat{\hat{Y}}=-0,8923+0,5157 * * X$ & 0,69 \\
\hline
\end{tabular}

** Significativo a $1 \%$ de probabilidade pelo teste $\mathrm{F}$.

** Significant at $1 \%$ probability by $F$ test.

gastrintestinal. De acordo com Van Soest et al. (1998), caprinos apresentam tempo de retenção de partículas no rúmen menor que o de bovinos, o pode que determinar maior capacidade de ingestão.

A redução linear verificada para o consumo de $\mathrm{PB}$ com o aumento do nível de FDNF das rações, nas diversas formas de expressão, pode ser atribuída à diminuição no consumo de MS, visto que as dietas eram isonitrogenadas. A redução linear $(\mathrm{P}<0,01)$ no consumo de EE pode ser atribuída à redução do consumo de MS e à menor participação deste nutriente nas dietas com maior teor de FDNF e, portanto, com menor teor de concentrado (Tabela 2).
O consumo de CHT diminuiu linearmente $(\mathrm{P}<0,01)$ quando expresso em $\mathrm{kg} / \mathrm{dia}$, \% PV e g/kg PV ${ }^{0,75}$, em razão da diminuição do consumo de MS, uma vez que o conteúdo de CHT entre as dietas experimentais (Tabela 2) foi similar. O consumo de CNE, da mesma forma, diminuiu linearmente $(\mathrm{P}<0,01)$ com a elevação do teor de FDNF das dietas, o que pode ser explicado pela redução da participação de concentrado à medida que se aumentou o teor de FDNF das rações.

$\mathrm{Na}$ Tabela 5 constam os valores referentes à produção e composição do leite, ao peso vivo, ao peso metabólico e ao ganho de peso diário dos animais submetidos aos diferentes níveis de FDNF. 
Tabela 5 - Valores médios de PV, peso metabólico ( $\left.\mathrm{PV}^{0,75}\right)$, ganho de peso (GMD), produção e composição do leite, de acordo com os teores de FDNF das dietas

Table 5 - Average value for body weight (BW), metabolic weight (BW $\left.{ }^{0.75}\right)$, weight gain (ADG), milk yield and composition according to the dietary FNDF levels

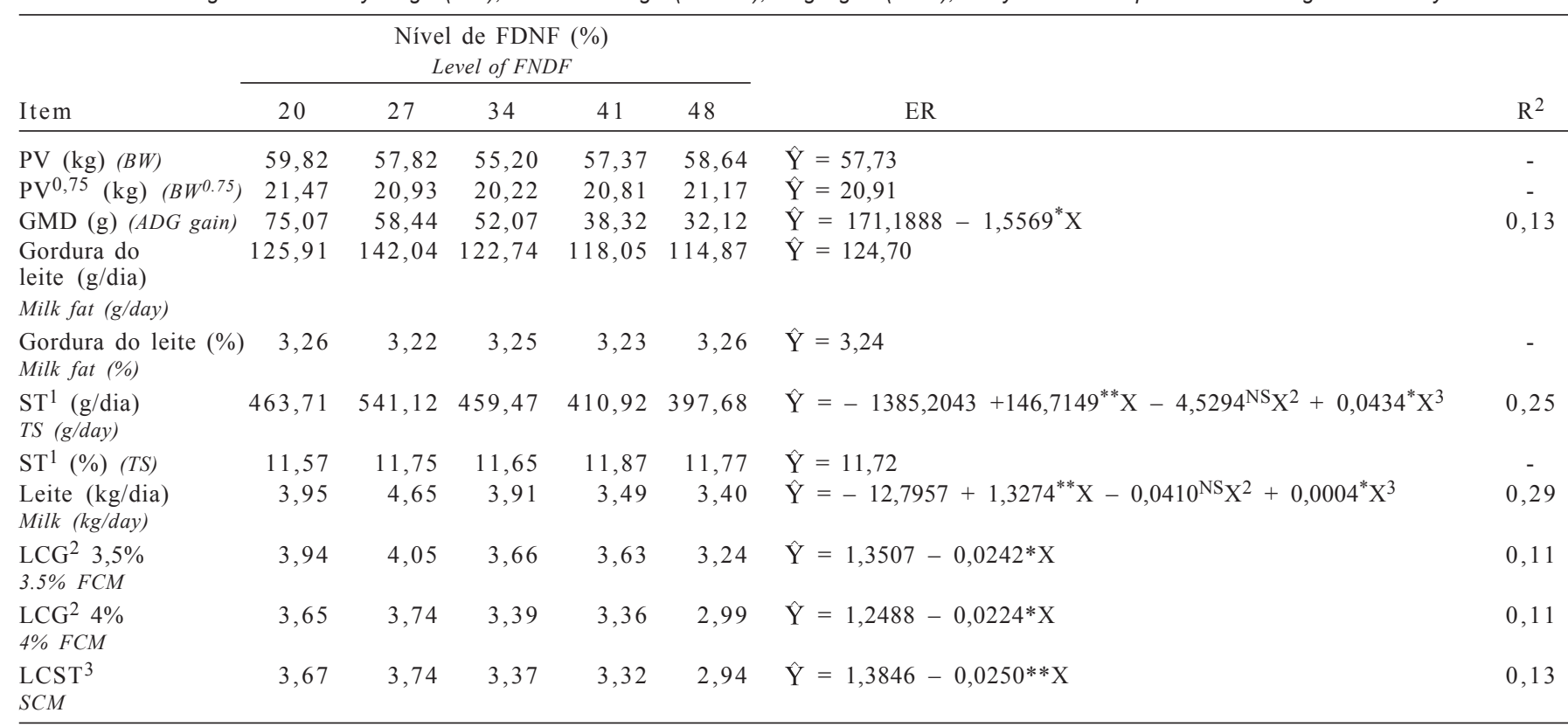

$\mathrm{NS}=$ não-significativo, * $\mathrm{e}^{* *}$ significativo a 5 e $1 \%$ de probabilidade, respectivamente, pelo teste $\mathrm{F}$ (NS = not significant, * and ${ }^{* *}$ significant at 5 and $1 \%$ probability, respectively, by F test).

1 ST - Sólidos totais (total solids), ${ }^{2}$ LCG - Leite corrigido para gordura (fat corrected milk), ${ }^{3}$ LCST - Leite corrigido para sólidos totais (total solid corrected milk).

Os resultados indicam efeito do nível de FDNF das dietas sobre o desempenho produtivo das cabras do experimento, enfatizando-se que a dieta elaborada para conter $27 \%$ de FDNF foi a que proporcionou a maior produção de leite e, em contraposição, as cabras alimentadas com dietas de maior conteúdo de FDNF foram as que apresentaram menor produção.

O efeito do nível de fibra da dieta sobre a produção de leite ocorre de forma direta e pode determinar restrição na ingestão de MS, e principalmente de energia, comprometendo a produção. O consumo de EL diminuiu com o aumento do nível de FDNF da ração (Tabela 3), o que determinou redução na produção de leite. Hussain et al. (1996) afirmam que a produção de leite é altamente dependente da quantidade total de energia consumida, o que está de acordo com Morand-Fehr \& Sauvant (1980), que registraram correlação positiva entre consumo de energia e produção de leite e negativa entre produção de leite e conteúdo de fibra da forragem. Da mesma forma, Smith (1976) e Briceno et al. (1987) observaram efeito linear significativo do consumo de energia sobre a produção de leite.

O teor de gordura do leite não diferiu entre os tratamentos, apresentando valor médio de 3,24\%. Nesse sentido, é importante salientar que o efeito da efetividade física da fibra dietética (FDNfe) é preponderante sobre o percentual de gordura do leite. De acordo com Lammers et al. (1996), reduções nos teores de fibra nas dietas promoveram diminuição no tempo gasto com mastigação (comendo e ruminando) e no pH ruminal, em razão do menor fluxo de saliva para o rúmen, reduzindo, conseqüentemente, o fluxo de substâncias tamponantes, proporcionando um ambiente ruminal desfavorável para o crescimento de microrganismos celulolíticos, reduzindo a relação acetato:propionato e o teor de gordura do leite. Como o teor de gordura não foi influenciado pelos níveis de fibra, pode-se inferir que a redução do teor de fibra da dieta não ocasionou falta de efetividade.

O teor de sólidos totais do leite não foi influenciado pela quantidade de fibra na dieta, demonstrando pequena variação entre os tratamentos. A produção de leite corrigida para gordura $(3,5$ ou $4 \%$ ) diminuiu com o aumento do teor de FDNF, conseqüência da redução da produção de leite observada nessas condições.

Na Figura 1 é apresentada a eficiência de utilização da energia metabolizável (EM) ingerida para produção de leite, de acordo com o teor de FDNF das dietas. A menor eficiência $(0,36)$ foi obtida com a dieta contendo $20 \%$ de FDNF e a melhor eficiência $(0,48)$, com a dieta com $48 \%$ de FDNF. Portanto, numericamente, a eficiência de conversão da EM consumida em produção de leite tendeu a aumentar com o incremento do teor de fibra da ração.

Quando se utilizou o procedimento Linear Response Plateau do programa estatístico SAEG (UFV, 1997), o qual ajusta modelos de regressão descontínuos, verificou-se 


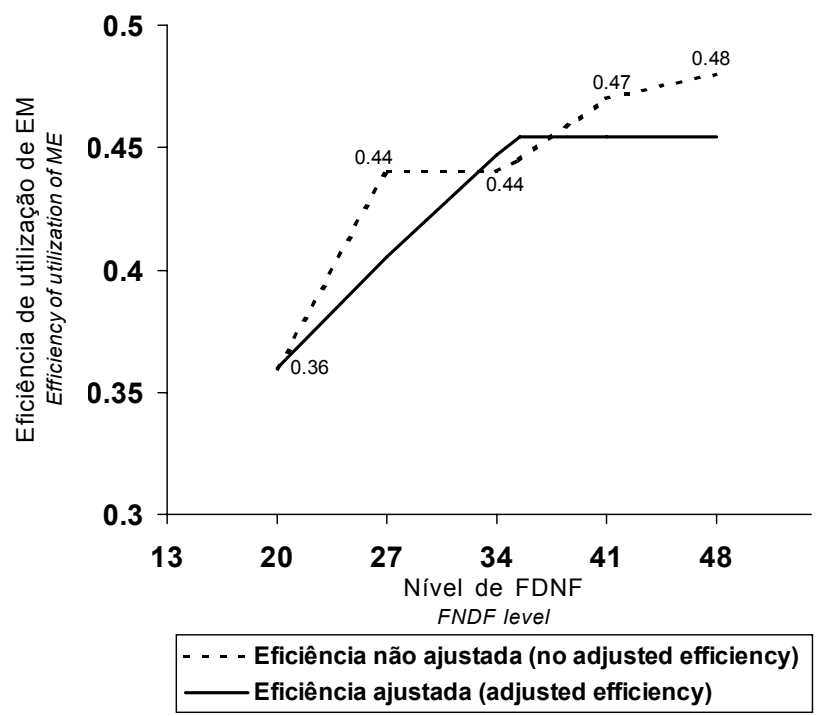

Figura 1 - Eficiência de utilização da energia metabolizável consumida para produção de leite, de acordo com o teor de FDNF da dieta.

Figure 1 - Efficiency of utilization of metabolizable energy for milk production according to the dietary FNDF levels.

que, a partir de $20 \%$ de FDNF, a eficiência aumentou 0,0054 a cada unidade de FDNF utilizada até atingir um plateau de 0,45 , obtido com uma dieta contendo $35,4 \%$ de FDNF. A equação de regressão ajustada obtida foi $\hat{Y}=0,2635+0,0054$ FDNF, para FDNF $<35,4$ e $\hat{Y}=0,4544$, para FDNF $\geq 35$, 4 . Com base nos resultados obtidos, pode-se inferir que a melhor eficiência de utilização da EM para produção de leite foi obtida com o nível de $35,4 \%$ de FDNF na dieta, o qual deveria ser recomendado como nível ótimo para formulação de rações nas condições desse experimento. Contudo, isso não significa que maior ou menor teor de FDNF não possa ser recomendado, pois isso depende da conveniência econômica do momento, a qual dependerá do custo da ração e da produção de leite dos animais.

\section{Conclusões}

Os consumos de MS, MO, PB, EE, CHT, CNE e EL diminuíram com o aumento do teor de FDNF nas rações de cabras em lactação, o que pode comprometer o desempenho produtivo dos animais. Os consumos de FDN, FDNF e FDA, no entanto, cresceram linearmente com o incremento do teor de FDNF, não se observando, portanto, capacidade máxima de ingestão da fibra.

Quando se utilizam altos teores de fibra na ração de caprinos, ocorre diminuição da produção de leite.

O nível de 35,4\% de FDNF pode ser recomendado na formulação de rações para cabras em lactação.

\section{Literatura Citada}

AGRICULTURAL AND FOOD RESEARCH COUNCIL - AFRC. Energy and protein requirements of ruminants. Wallingford: CAB International, 1993. 159p.

ARAÚJO, G.G.L.; SILVA, J.F.C.; VALADARES FILHO, S.C. et al. Consumo e digestibilidade total dos nutrientes de dietas contendo diferentes níveis de volumoso, em bezerros. Revista Brasileira de Zootecnia, v.27, n.2, p.345-354, 1998

BRICENO, J.V.; Van HORN, H.H.; HARRIS JR., B. et al. Effects of neutral detergent fiber and roughage source on dry matter intake and milk and composition of dairy cows. Journal of Dairy Science, v.70, n.2, p.298-308, 1987.

BULL, L.S.; BAUMGARDT, B.R.; CLANCY, M. Influence of calorie density on energy intake by dairy cows. Journal of Dairy Science, v.59, n.6, p.1078-1086, 1976.

BURGER, P.J.; PEREIRA, J.C.; COELHO DA SILVA, J.F. et al. Consumo e digestibilidade aparente total e parcial em bezerros Holandeses alimentados com dietas contendo diferentes níveis de concentrado. Revista Brasileira de Zootecnia, v.29, n.1, p.206-214, 2000.

FORBES, J.M. Voluntary food intake and diet selection by farm animals. Madison: CAB International, 1995. 532p.

GAINES, W.L. The energy basis of measuring milk yield in dairy cows. Illinois Agricultural Experiment Station Bulletin 308. 1928. 40p.

HUSSAIN, Q.; HAVREVOLL, Ø.; EIK, L.O. Effect of type of roughage on feed intake, milk yield and body condition of pregnant goats. Small Ruminant Research, v.22, p.131-139, 1996.

LAMMERS, B.P.; BUCKMASTER, D.R.; HEINRICHS, A.J. A simple method for the analysis of particle sizes of forage and total mixed rations. Journal of Dairy Science, v.79, n.5, p.922928, 1996.

MERTENS, D.R. Using neutral detergent fiber to formulate dairy rations and estimate the net energy content of forages. Ithaca: Cornell University, 1983. p.60-69.

MERTENS, D.R. Predicting intake and digestibility using mathematical models of ruminal function. Journal of Animal Science, v.64, p.1548-1558, 1987.

MERTENS, D.R. Regulation of forage intake. In: FAHEY, G.C. (Ed.) Forage quality, evaluation, and utilization. Madison: American Society Agronomy, 1994. p.450-493.

MERTENS, D.R. Using fiber and carbohydrate analysis to formulate dairy rations. Journal of Animal Science, v.80, p.1463-1481, 1996.

MOE, P.W.; TYRRELL, H.F. Estimating metabolizable and net energy of feeds. In: INTERNATIONAL SYMPOSIUM ON FEED COMPOSITION, ANIMAL NUTRIENT REQUIREMENTS, AND COMPUTERIZATION OF DIETS, 1., 1967, Logan. Proceedings... Logan: Utah State University, 1976. p.232-237.

MORAND-FEHR, P.; SAUVANT, D. Composition and yield of goat milk as affected by nutritional manipulation. Journal of Dairy Science, v.63, p.1671-1680, 1980.

NATIONAL RESEARCH COUNCIL - NRC. Nutrient requirements of dairy cattle. 6.ed. Washington, D.C.: National Academy of Science, 1989. $158 \mathrm{p}$.

NATIONAL RESEARCH COUNCIL - NRC. Nutrient requirements of dairy cattle. 7.ed. Washington, D.C.: National Academy of Science, 2001. 381p.

RESENDE, F.D.; QUEIROZ, A.C.; ALENCAR, C.A.A. et al. Rações com diferentes níveis de fibra em detergente neutro na alimentação de bovídeos em confinamento. Revista Brasileira de Zootecnia, v.23, n.3, p.366-376, 2004.

RODRIGUES, M.T. Uso de fibras em rações de ruminantes. In CONGRESSO NACIONAL DOS ESTUDANTES DE ZOOTECNIA, 1998, Viçosa, MG. Anais... Viçosa, MG: Universidade Federal de Viçosa, 1998. p.139-171.

SEARLE, S.R. Linear models. New York: John Wiley \& Sons, 1971. $533 \mathrm{p}$. 
SILVA, D.J. Análise de alimentos (métodos químicos e biológicos). Viçosa, MG: Universidade Federal de Viçosa, 1990. 165p.

SILVA, H.F. Físico-química do leite e derivados: métodos analíticos. Juiz de Fora: Oficina de Impressão Gráfica Ltda. 1997. $190 \mathrm{p}$.

SMITH, N. Maximizing income over feed costs: Evaluation of production response relationship. Journal of Dairy Science, v.59, p.1193, 1976

SNIFFEN, C.J.; O'CONNOR, J.D.; Van SOEST, P.J. A net carbohydrate and protein system for evaluating cattle diets: II. Carbohydrate and protein availability. Journal of Animal Science, v.70, p.3562-3577, 1992.

TYRREL, H.F.; REID, J.T. Prediction of the energy value of cows milk. Journal of Dairy Science, v.48, n.9, p.12151223, 1965.

UNIVERSIDADE FEDERAL DE VIÇOSA - UFV. SAEG - Sistema de análises estatísticas e genéticas. Versão 7.1.Viçosa, MG: 1997. 150p. (Manual do usuário).
Van SOEST, P.J. Nutritional ecology of the ruminant. 2.ed. Ithaca: Comstock, 1994. 476p.

Van SOEST, P.J.; McCAMMON-FELDMAN, B.; CANNAS, A. The feeding and nutrition of small ruminants: application of the cornell discount system to the feeding of dairy goats and sheep. In: CORNELL NUTRITION CONFERENCE FOR FEED MANUFACTURES. Proceedings... Ithaca: Cornell University, 1998. p.95-104.

WALDO, D.R. Factors influencing voluntary intake of forages. In NATIONAL CONFERENCE ON FORAGE QUALITY EVALUATION AND UTILIZATION, 1970, Lincoln. Proceedings... Lincoln: Nebraska Center for Continuing Education, 1970. p.1-22. 